\title{
Asociación entre hábitos alimentarios y acné del adulto
}

\author{
Association between adult acne and dietary behaviors
}

\section{Comentado de:}

Penso L, et al. JAMA Dermatol. June 10, 2020;156(8):854-862. PMID:32520303. ${ }^{1}$

\section{Objetivo}

Establecer una relación entre los hábitos de alimentación y la presencia de acné del adulto, pasado o actual.

\section{Diseño, lugar y pacientes}

Se realizó un estudio transversal como parte del estudio NutriNet-Santé, que es un estudio de cohorte observacional en curso que había iniciado en Mayo de 2009 en el Departamento de dermatología, Hospital de Mondor en Paris, Francia. Se llevó a cabo desde noviembre de 2018 hasta julio de 2019.

Participaron 24.452 individuos quienes respondieron cuestionarios en línea, acerca de su nivel de acné, pasado o presente y su comportamiento alimentario.

\section{Evaluación de los factores de riesgo}

Se evaluó el consumo diario de alimentos de los participantes en: 1) tipo de alimento, en gramos por día de: frutas, verduras, leche, carne, etc. y 2) tipo de nutriente en gramos o miligramos por día de: vitaminas, zinc, fibras, carbohidratos, lípidos, proteínas, etc. Además, los participantes respondieron acerca de sus características sociodemográficas, antropométricas, estilo de vida, actividad física y antecedentes personales patológicos.

\section{Medición de resultados principales}

Para evaluar la asociación del consumo de alimentos y nutrientes entre individuos con acné pasado o presente en comparación con individuos que nunca tuvieron acné, se utilizaron modelos de regresión logística uninomial y multinomial (en este último caso ajustando los resultados por posibles variables de confusión como edad, sexo, actividad física, tabaquismo, nivel educativo, ingesta diaria de energía, número de registros dietéticos completados y síntomas depresivos). Los resultados se expresaron como odds ratios $(\mathrm{OR}) \mathrm{u}$ odds ratios ajustados (ORa), respectí- vamente, con sus correspondientes intervalos de confianza del $95 \%$ (IC95\%).

\section{Resultados principales}

Los 24.453 participantes tenían una media de edad de 57 (DE 14) años; 18.327 (75\%) eran mujeres y 11.324 (46\%) reportaron tener o haber tenido acné.

El análisis uninomial no ajustado, mostró que los participantes que habían experimentado acné en el pasado o presentaban acné en el presente, comparados con aquellos que nunca habían experimentado acné, consumían significativamente más leche (OR 1,28; IC95\% 1,18 a 1,39), bebidas azucaradas $(2,19$; $1,94$ a 2,48$)$ chocolate con leche $(1,28 ; 1,19$ a 1,38$)$ snacks y comidas rápidas $(3,83 ; 3,34$ a 4,40$)$, y más productos ricos en grasas y azúcares $(4,35 ; 3,50$ a 5,41$)$; y significativamente menos carne $(0,39 ; 0,31$ a 0,48$)$, pescado $(0,17 ; 0,13$ a 0,23$)$, vegetales $(0,71 ; 0,66$ a 0,76$)$, fruta $(0,71 ; 0,67$ a 0,74$)$ y chocolate negro $(0,90 ; 0,84$ a 0,96$)$.

Luego de aplicar el modelo multinomial ajustado, tanto el consumo de leche (por vaso, ORa 1,12; IC95 \% 1,00 a 1,25; $p=0,04$ ), bebidas azucaradas (por vaso, 1,$18 ; 1,01$ a 1,$38 ; 0,04$ ), y alimentos ricos en azúcares y grasas (por porción, 1,54; 1,09 a 2,6; 0,01) se presentaron como factores asociados en forma independiente al acné actual.

\section{Conclusiones}

Este estudio muestra que el consumo de una dieta de tipo occidental con alimentos ricos en azúcares, grasas, bebidas azucaradas y leche se asocia a la presencia de acné del adulto. Se requieren nuevas investigaciones que puedan aportar evidencia a la prevención y el manejo del acné.

Fuente de financiamiento/Conflicto de interés de los autores: La fuente de financiamiento no fue reportada. Los autores declararon no presentar conflictos de interés.

\section{Comentario}

El acné es la enfermedad inflamatoria crónica más frecuente de la piel, suele afectar a población joven ${ }^{2,3}$, sin embargo, el acné del adulto, que se da en individuos mayores de 25 años, tiene una prevalencia en occidente de aproximadamente el $50 \%$

El acné produce un impacto negativo en la calidad de vida de quienes lo padecen, con reportes de: baja autoestima, aislamiento social y depresión. Tiene una fisiopatogenia compleja multifactorial, en la cual tanto los factores genéticos, endocrinos como ambientales son fundamentales en el desarrollo o la exacerbación del acné. Dentro de los factores ambientales como potenciales implicados encontramos: ciertos productos cosméticos, el tabaco, el estrés, la polución ambiental y la alimentación 5,6 .

La asociación entre dieta y acné ha generado un gran número de investigaciones en las últimas décadas. Múltiples artículos demuestran que dietas con elevados índices glucémicos (dietas occidentales) se asocian con acné ${ }^{6-9}$; similares observaciones pudieron demostrarse con el consumo de leche y la presencia de acné ${ }^{10}$.

Las dietas occidentales, determinan elevados niveles plasmáticos de insulina y de factor de crecimiento símil insulina 1 (por sus siglas en inglés, IGF-1) que actuando en la unidad pilosebácea, induce la proliferación de queratinocitos y sebocitos ${ }^{11}$. Además, se ha demostrado que estimula un aumento de la producción de andrógenos, incrementa el estrés oxidativo y la inflamación, promoviendo el desarrollo del acné ${ }^{12,13}$

Por otro lado, el consumo de leche, estimula la producción hepática de IGF-1 y con esto se elevan los niveles plasmáticos de insulina. Un meta análisis reciente encontró una relación positiva entre el consumo de lácteos (leche entera, leche baja en grasa y leche descremada) y la aparición de acné, pero no una asociación significativa entre el consumo de yogur o queso y el desarrollo del acné ${ }^{14}$ 
Es importante destacar que la investigación disponible no demuestra que la dieta causa acné, sino que podría influir o agravar el acné existente

Más allá de esto, los datos publicados hasta el momento presentan limitaciones, como bajo número de pacientes, incluyen solo pacientes adolescentes, y no investigan la exposición a múltiples alimentos.

Son necesarios nuevos estudios para evaluar si las intervenciones dietarias pueden mejorar o prevenir el acné y cómo el tamaño del efecto de tales intervenciones se compara con los tratamientos estándar.

\section{Conclusiones de la comentadora}

Este articulo aporta información valiosa proveniente de una gran cohorte de adultos, con datos precisos y oportunos sobre la ingesta de la dieta occidental (rica en productos de origen animal, grasas y azúcares) y la presencia de acné concomitante.

Noelia Capellato [ Servicio de dermatología, Hospital Italiano de Buenos Aires. noelia.capellato@hospitalitaliano.org.ar ]

Capellato N. Asociación entre hábitos alimentarios y acné del adulto. Evid Actual Pract Ambul. 2021;24(1):e002091. Comentado de: Penso L, et al. Association Between Adult Acne and Dietary Behaviors. JAMA Dermatol. 2020;156(8):854-862. PMID: 32520303.

\section{Referencias}

1. Penso L, Touvier M, Deschasaux M, et al. Association Between Adult Acne and Dietary Behaviors: Findings From the NutriNet-Santé Prospective Cohort Study. JAMA Dermatol. 2020;156(8):854-862. Available from: 10.1001/jamadermatol.2020.1602.

2. Degitz K, Placzek M, Borelli C, et al. Pathophysiology of acne. J Dtsch Dermatol Ges. 2007;5(4):316-323. Available from: $10.1111 / j .1610-0387$. 2007.06274.x;https://dx.doi.org/10.1111/j.1610-0387.2007.06274.x.

3. Hay RJ, Johns NE, Williams HC, et al. The global burden of skin disease in 2010: an analysis of the prevalence and impact of skin conditions. $J$ Invest Dermatol. 2014;134(6):1527-1534.

4. Cunliffe WJ, Gould DJ. Prevalence of facial acne vulgaris in late adolescence and in adults. BMJ. 1979;1(6171):1109-1110. Available from: 10.1136/bmj.1.6171.1109; https://dx.doi.org/10.1136/bmj.1.6171.1109.

5. Rademaker M, Garioch JJ, Simpson NB. Acne in schoolchildren: no longer a concern for dermatologists. BMJ. 1989;298(6682):1217-1219. Available from: 10.1136/bmj.298.6682.1217;https://dx.doi.org/10.1136/bmj.298.6682.1217.

6. Stewart TJ, Bazergy C. Hormonal and dietary factors in acne vulgaris versus controls. Dermatoendocrinol. 2018;10(1):e1442160-e1442160. Available from: 10.1080/19381980.2018.1442160;https://dx.doi.org/10.1080/19381980.2018.1442160.

7. Ismail NH, Manaf ZA, Azizan NZ. High glycemic load diet, milk and ice cream consumption are related to acne vulgaris in Malaysian young adults: a case control study. BMC Dermatol. 2012;12(1):13-13. Available from: 10.1186/1471-5945-12-13;https://dx.doi.org/10.1186/1471-5945-12-13.

8. Çerman A, Aktaş E, Altunay i, et al. Dietary glycemic factors, insulin resistance, and adiponectin levels in acne vulgaris. J Am Acad Dermatol. 2016;75(1):155-162. Available from: 10.1016/j.jaad.2016.02.1220;https://dx.doi.org/10.1016/j.jaad.2016.02.1220.

9. Berra B, Rizzo AM. Glycemic Index, Glycemic Load: New Evidence for a Link with Acne. J Am Coll Nutr. 2009;28(sup4):450S-454S. Available from: 10.1080/07315724.2009.10718111;https://dx.doi.org/10.1080/07315724.2009.10718111.

10. Adebamowo CA, Spiegelman D, Danby FW, et al. High school dietary dairy intake and teenage acne. J Am Acad Dermatol. $2005 ; 52(2): 207-214$. Available from: 10.1016/j.jaad.2004.08.007; https://dx.doi.org/10.1016/j.jaad.2004.08.007.

11. Millward DJ, Layman DK, Tomé D, et al. Protein quality assessment: impact of expanding understanding of protein and amino acid needs for optimal health. Am J Clin Nutr. 2008;87(5):1576S-1581S. Available from: 10.1093/ajcn/87.5.1576s;https://dx.doi.org/10.1093/ajcn/87.5.1576s.

12. Rahaman SMA, De D, Handa S, et al. Association of insulin-like growth factor (IGF)-1 gene polymorphisms with plasma levels of IGF-1 and acne severity. J Am Acad Dermatol. 2016;75(4):768-773. Available from: 10.1016/j.jaad.2016.05.019;https://dx.doi.org/10.1016/j.jaad.2016.05.019.

13. Tasli L, Turgut S, Kacar N, et al. Insulin-like growth factor-I gene polymorphism in acne vulgaris. J Eur Acad Dermatol Venereol. $2013 ; 27(2): 254-257$.

14. Aghasi M, Golzarand M, Shab-Bidar S, et al. Dairy intake and acne development: A meta-analysis of observational studies. Clin Nutr. 2019;38(3):1067-1075. Available from: 10.1016/j.clnu.2018.04.015;https://dx.doi.org/10.1016/j.clnu.2018.04.015. 